\title{
Molecular Phylogenetics and Evolution
}

Nomenclatural stability does not justify recognition of paraphyletic taxa: a response to Scherz et al. (2016)

Pedro L. V. Peloso ${ }^{\mathrm{a}, \mathrm{b},{ }^{*}}$, Christopher J. Raxworthy ${ }^{\mathrm{b}}$, Ward C. Wheeler ${ }^{\mathrm{c}}$, Darrel R. Frost ${ }^{\mathrm{b}}$,

${ }^{a}$ Museu Paraense Emílio Goeldi, Coordenação de Zoologia. Avenida Perimetral, 1901, Terra Firme, CEP 66077-530, Belém, Pará, Brasil. Present Address. E-mail: pedropeloso@gmail.com

${ }^{\mathrm{b}}$ Division of Vertebrate Zoology (Herpetology), and ${ }^{\mathrm{c}}$ Division of Invertebrate Zoology, American Museum of Natural History, Central Park West at 79th Street, 10024, New York, NY, USA.

* Corresponding Author 


\begin{abstract}
Peloso et al. (2015: PELOSO) published a comprehensive phylogenetic study of the frog family Microhylidae, which resulted in the discovery that several taxa were not monophyletic. To remedy this, a series of nomenclatural changes were proposed (several generic synonymies and two new subfamilies named). A recent study published in this journal by Scherz et al. (2016: SCHERZ), provided a novel phylogeny for the Malagasy subfamily Cophylinae. SCHERZ dispute the analyses and taxonomic conclusions of PELOSO. Their study is, however, based on substantial reduction of data from the PELOSO study, limited addition of new data, and different analytical methods. In spite of the fact that their own results are consistent with the taxonomy of PELOSO, SCHERZ reject that conservative taxonomy and suggest the revalidation of Platypelis (from the synonymy of Cophyla), the revalidation of Stumpffia (from the synonymies of Rhombophryne), and the creation of at least two new genera (only one named therein). In doing so, SCHERZ accept the recognition of likely paraphyletic taxa, with Stumpffia paraphyletic in their parsimony analysis. Herein, we provide a response to several points raised in SCHERZ: (1) we discuss issues with their interpretation (and selective use) of available phylogenetic and phenotypic evidence; (2) and provide a new phylogenetic analysis of all the data in PELOSO and SCHERZ combined. In the new analysis Stumpffia is paraphyletic with respect to Rhombophryne, whereas Cophyla and Platypelis are both monophyletic and sister taxa. We provide a case for the use of the taxonomy suggested in PELOSO.
\end{abstract}

\title{
Keywords
}


Amphibia; Cophylinae; Madagascar; Microhylidae; Phylogeny; Taxon-Naming Criteria (TNC); 


\section{Introduction}

Microhylidae represent approximately $8.8 \%$ of the global frog diversity and are found in almost every tropical landmass on earth. Despite dense sampling and repeated attempts to infer phylogenetic relationships among members of the family (e.g., de Sá et al., 2012; Peloso et al., 2015; van der Meijden et al., 2007), relationships, particularly among the nominal subfamilies, are largely unstable, and several genera and subfamilies are still suspected to be para- or polyphyletic.

Peloso et al. (2015: hereafter PELOSO) performed a sensitivity analyses (sensu Wheeler, 1995) on a variety of combinations of taxa (up to 142 taxa) and genomic data (up to 73 loci) to infer the phylogeny of microhylids. Based on their phylogenetic results, PELOSO reviewed the classification of Microhylidae suggesting several taxonomic updates to generic classification, and also naming two new subfamilies in the process. After PELOSO, Microhylidae was considered to be composed of 13 subfamilies:

\subsection{The generic content in Cophylinae}

Cophylinae is endemic to Madagascar and is composed of 72 named species (third largest microhylid subfamily), plus an apparent high number of unnamed taxa (Köhler et al., 2010; Perl et al., 2014; Scherz et al., 2016; Wollenberg et al., 2008). The phylogeny of Cophylinae has received considerable attention compared to most other subfamilies (Andreone et al., 2005; Blommers-Schlösser and Blanc, 1993; Scherz et al., 2016; Wollenberg et al., 2008); hence, multiple alternate hypotheses of relationships have been suggested. PELOSO sampled 32 cophyline taxa in their analyses, including six of the seven genera recognized at the time (excepting Madecassophryne, for which tissue 
samples are unavailable). The results in PELOSO corroborated previous suspicions that some cophyline genera are not monophyletic: Platypelis (paraphyletic with respect to Cophyla), Stumpffia, and Rhombophryne (with respect to each other). To remedy this, PELOSO suggested, among other things: (1) Platypelis Boulenger, 1882 should be treated as a synonym of Cophyla Boettger, 1880; and (2) Stumpffia Boettger, 1881 should be treated as a synonym of Rhombophryne Boettger, 1880.

\subsection{Scherz et al. (2016)}

A recent study published in this journal, by Scherz et al. (2016: hereafter SCHERZ), disputed the data, results and taxonomic conclusions of PELOSO. The principal taxonomic actions of SCHERZ were to: (1) reject the synonymy of Platypelis with Cophyla, (2) reject the synonymy of Stumpffia with Rhombophryne, and (3) create a new genus (Anilany).

In support of their taxonomic decisions, SCHERZ provided novel phylogenetic analyses (with many added analytical assumptions) of Cophylinae, which also purported to constitute "a re-analysis of the cophyline members of the PELOSO dataset". However, when doing so, SCHERZ inexplicably excluded a large fraction of the PELOSO dataset. $75 \%$ of the taxa and $97 \%$ of the genetic data from PELOSO were completely discarded without much discussion or justification. Despite the availability of up to 73 loci from the PELOSO study, data for 71 loci were discarded. Only data from the mitochondrial genes $16 S$ ribosomal RNA (16S) and Cytochrome Oxidase Subunit I (COI) generated by PELOSO were included by SCHERZ. A substantial amount of data available for 
outgroup taxa were also ignored-SCHERZ deleted all data for non-Malagasy microhylids.

SCHERZ employed two methods for phylogenetic inference: Bayesian inference (via MrBayes) and parsimony (via TNT) — their implementations based on a two-step procedure (multiple sequence alignment + phylogenetic inference: i.e., similarityalignment). Nevertheless, SCHERZ largely ignored the results from their own parsimony analysis (which do not support their preferred taxonomy) in favor of the Bayesian topology (which marginally supports their preferred taxonomy) ${ }^{1}$. Furthermore, SCHERZ never discussed the fact that their discovery operations (similarity-alignment) are based on conspicuously different theoretical foundations than that of PELOSO (direct optimization: Sankoff, 1975; Wheeler, 1996 - tree-alignment). Several authors have discussed the issue of assessing DNA sequence homology, whereas many of them agree that multiple-sequence alignment is best performed with explicit reference to the phylogeny (Felsenstein, 1988, p. 525; Sankoff, 1975; Sankoff and Cedergren, 1983; Wheeler, 1996).

SCHERZ's arguments for the rejection of the taxonomic review of PELOSO are largely based on: (1) sample misidentifications in the dataset of PELOSO; (2) the claim that the changes are unnecessary to attain a monophyletic classification; and (3) that SCHERZ's classification promotes taxonomic stability. We discuss these topics below.

\section{A response to Scherz et al. (2016)}

\footnotetext{
${ }^{1}$ Their Bayesian topology does support the monophyly of Cophyla, Platypelis, Rhombophryne, and Stumpffia, albeit with very low posterior probability.
} 
SCHERZ "re-analysis" of PELOSO, and the conclusions drawn from it, are questionable. In this section, we address several logical, analytical, and theoretical issues in SCHERZ's study.

\subsection{Sample misidentifications and their impact in the proposed taxonomy}

SCHERZ provided a series of corrections and updates to identifications of samples used in PELOSO. The authors claim that these identification mistakes "caused erroneous genus-level changes within the Cophylinae", but fail to recognize that most of these changes were not a result of misidentifications. Rather, the changes proposed by PELOSO stem from the fact that paraphyletic taxa have been historically recognized in the subfamily.

SCHERZ thoroughly reviewed the identification of the genetic samples of cophyline taxa used in PELOSO. This was accomplished by direct comparisons with new (published with SCHERZ) and legacy (GenBank) sequences. The potential sources of the identification errors were discussed in SCHERZ (Supplementary Material). SCHERZ's co-author Miguel Vences (MV), through the Technische Universität Braunschweig, supplied many (almost 30\%) of the mislabeled samples used in PELOSO. Some of these mislabeled samples included tissues supposedly taken from type specimens of species collected and described by MV (and colleagues). A sample labeled Rhombophryne matavy D'Cruze, Köhler, Vences, and Glaw, 2010 in PELOSO, turned out to represent a tissue of the holotype of Plethodontohyla fonetana Glaw, Köhler, Bora, Rabibisoa, Ramilijaona, and Vences, 2007, whereas a sample labeled as one of the paratypes of Rhombophryne mangabensis Glaw, Köhler, and Vences, 2010, was re-identified as an 
unnamed species of Stumpffia. This, however, does not exempt PELOSO from the responsibility of actually incorporating these samples into their work. Clearly, however, future workers should beware of identifications of frog tissue samples provided by the Technische Universität Braunschweig (including type specimens).

Regardless of the source of the misidentifications, SCHERZ's statement that these mistakes are the main source of erroneous changes to the taxonomy is misleading. Contrary to their claim, the evidence reported by PELOSO was not the sole argument for the taxonomic changes proposed. Figure 1 shows the cophyline section of the optimal tree from PELOSO with updated and corrected sample IDs (as corrected in SCHERZ) — this reevaluation shows that even with updated sample identifications (assuming the identifications provided in SCHERZ are 100\% correct), the taxonomy proposed in PELOSO is monophyletic, whereas the one suggested by SCHERZ is still not-i.e., after sample identification corrections Cophyla is still nested within Platypelis (rendering the latter paraphyletic), and Stumpffia is nested within Rhombophryne (rendering the latter paraphyletic).

Finally, we emphasize that there is abundant phylogenetic evidence supporting the taxonomy advocated in PELOSO — this comes not only from the dataset and analyses in PELOSO itself (Fig. 1), but also from previously published papers, many by the authors in SCHERZ (e.g., Perl et al., 2014; Pyron and Wiens, 2011; Rakotoarison et al., 2015; Scantlebury, 2013; Wollenberg et al., 2008). The sample identification errors are, therefore, insufficient to reject the taxonomy proposed in PELOSO.

[[FIGURE 1 HERE]] 


\subsection{To name or not to name?}

SCHERZ argued that their taxonomy is formalized based on the Taxon-Naming Criteria (TNC) proposed by Vences et al. (2013). However, the criteria were applied inconsistently. When advocating for the TNCs, Vences et al. (2013) established a series of considerations and priorities to be addressed when suggesting name changes in a given group's classification.

Vences et al. (2013) suggested that economy of change should be "a main priority for biological classification”. Vences et al. (2013) further considered that monophyly, clade stability, and phenotypic diagnoses should also receive high priority in taxonomic decisions. SCHERZ allegedly follow these priorities, but favor a taxonomy that (i) created a monotypic genus (Anilany) of unstable relationships (possibly rendering Stumpffia paraphyletic, even according to their own parsimony analyses), and (ii) will likely require further generic changes in the near future - at least two additional new genera are already necessary (one for Stumpffia tridactyla, and another to two unnamed species previously identified, respectively, as Stumpffia spCa15 and Stumpffia spCa16 on the basis of molecular data). Moreover, we argue that following the taxonomy suggested in SCHERZ actually does not entirely satisfy any of the priority TNCs proposed in Vences et al. (2013).

Monophyly_There is mounting evidence that Stumpffia and Rhombophryne are not monophyletic (Peloso et al., 2015; Perl et al., 2014; Scherz et al., 2016). PELOSO found that Rhombophryne is paraphyletic with respect to Stumpffia. SCHERZ, even after they named a new genus to rescue Stumpffia from paraphyly, and recovered S. tridactyla 
as not being part of that genus on their parsimony analysis. Our own analysis (see below) also failed to recover monophyly of Stumpffia-S. tridactyla is the sister taxon of Anilanyi (but with very low support: Fig. 2).

The monophyly of Platypelis is also not well established. Both PELOSO and Rakotoarison et al. (2015) provided evidence that Platypelis may be paraphyletic with respect to Cophyla. Our analysis supports the monophyly of both genera with acceptable support values (Fig. 3).

Stability-An evaluation of recent phylogenetic analyses of Cophylinae clearly shows that monophyly and relationships among some cophyline genera are largely unstable with respect to dataset and method of analysis (Table 1). SCHERZ claim they are confident that their taxonomy will entail fewer future rearrangements (p. 380), but they did not provide a solution to the potential non-monophyly of Stumpffia due to the ambiguous position of $S$. tridactyla. Moreover, they did not address the problem that the clade formed by Rhombophryne spCa07 and Stumpffia Ca34 (both unnamed) is the sister clade of Stumpffia in their Bayesian analysis, but deeply nested in Rhombophryne in their parsimony analysis (also nested within Rhombophryne in our analysis, see Figs. 2, 4). The taxonomy of PELOSO avoids both of these problems.

Diagnosable taxa-The consensus among authors working on Malagasy fauna is that the phenotypic diagnosis of most cophyline genera is extremely difficult, if at all possible. Even SCHERZ admit to that: "our revised classification is not free of ambiguities in diagnosing genera by morphology alone" (p. 380).

Therefore, it is relatively easy to argue that SCHERZ are not strictly following the TNCs, but rejecting ad hoc most of the provisions set forth by the criteria. In fact, and 
rather ironically, SCHERZ agree that the taxonomy proposed in PELOSO would also fit the TNCs and, in many cases, would be an even better fit for them: "It is true, however, that the two clades [Cophyla + Platypelis] together form a monophyletic group (satisfying the Stability of Monophyly TNC) and might together become more easily diagnosable in external morphology (which would satisfy the Diagnosibility TNC)" (SCHERZ: p. 377, taxon names in brackets were added herein).

\section{Re-analysis of SCHERZ's data reveals several analytical issues}

\subsection{NMDS: Biased coding forces separation between Stumpffia, Rhombophryne, and}

\section{Anilany}

The coding of morphological characters used by SCHERZ in their NMDS is inadequate to provide a meaningful morphological diagnosis of these genera. The characters were, in their own words, "chosen ad-hoc to maximize diagnostic power to distinguish the two taxa". We recoded some of the morphological characters used for the NMDS using a more objective coding method (Supplementary Data 1), and we also included Anilany in the matrix. The new analysis provided more robust results (e.g., smaller stress values despite a larger matrix) but also a less clear separation between Rhombophryne and Stumpffia. The two genera are still segregated by the analysis, although with significant overlap. The inclusion of Anilany in the NMDS provided no separation whatsoever between Anilany and Stumpffia.

The recoded matrix and results of the analyses are given as Supplementary Data (Supplementary Data S1). 


\subsection{A re-analysis of PELOSO's and SCHERZ's phylogenetic data}

SCHERZ deleted the vast majority of the data available from PELOSO (75\% of the taxa and $97 \%$ of the genetic data were deleted), including virtually all representatives from microhylid subfamilies other than Malagasy taxa. SCHERZ included a single nonMalagasy taxon, Kaloula pulchra (Microhylinae), which was used to root the tree. This approach is problematic for two reasons: (1) it implies the monophyly of Malagasy microhylids, which is not well established; and (2) it downplays the role of taxon sampling in phylogenetic inference- - the latter issue has been widely discussed in the literature (see Kirchberger et al., 2014; Wilberg, 2015 for recent examples), including in PELOSO.

To remedy the aforementioned issues, we re-analyzed the phylogenetic dataset of SCHERZ in combination with the totality of the data from PELOSO.

\subsubsection{Phylogenetic analysis of the combined data from PELOSO and SCHERZ}

Sequence data from both studies were obtained from DataDryad (SCHERZ, doi: 10.5061/dryad.1b2k5; PELOSO, doi: 10.5061/dryad.8112f). Overlapping loci ( $16 S$ and COI) were combined into single alignments, whereas redundant taxa (i.e., those present in both datasets) were manually removed. All loci were individually realigned with the MAFFT version 7.222 (Katoh et al., 2002) plugin in Geneious version R9 (Kearse et al., 2012) using the default parameters. All loci were then concatenated into a single dataset in Sequence Matrix (Vaidya et al., 2011). The combined dataset contained 292 taxa and 36458 characters (Supplementary Data S2). 
For comparability with the analysis presented in SCHERZ, we used a staticalignment approach to phylogenetic inference of the combined dataset. Parsimony analysis was performed in TNT version 1.1(Goloboff et al., 2008) with the xmult command, which implements a variety of search algorithms - Random Addition Sequences (RAS), Tree Bisection and Reconnection branch swapping (TBR), Tree Fusing (Goloboff, 1999), Sectorial Searches (Goloboff, 1999), and Tree Drifting (Goloboff, 1999). Search was allowed to run until the best solution was hit 1000 times (command hits 1000). Nodal support was assessed using Jackknife (Farris et al., 1996), estimated with 1000 replicates with five search iterations using xmult per replicate, and a removal rate of $\mathrm{e}^{-1}(=0.36)$ following the suggestion of Farris et al. (1996) that this is the value most congruent with bootstrapping. For both tree search and Jackknife analyses, gaps were treated as a fifth nucleotide state (default).

To test the influence in tree scores of differential placement of selected taxa, we manipulated the strict consensus topology by hand in Mesquite 3.0 (Maddison and Maddison, 2007). Trees were then read into PAUP 4.1 (Swofford, 2002) where we calculated the parsimony and maximum likelihood (ML) scores for the alternative topologies. ML scores were calculated assuming a single concatenated partition and a GTR+G model. Manipulations were restricted to the positions of Stumpffia tridactyla and the clade composed of ('Rhombophryne' spCa07 + 'Stumpffia' spCa34).

\section{Results and Discussion}

\subsection{Phylogenetic analysis}


The TNT analysis of the combined data from PELOSO and SCHERZ recovered 72 equally most parsimonious trees of 83100 unordered, equally weighted, transformations. The strict consensus of these trees requires 83464 transformations (see figures 2 and 3 for the Cophylinae section of the strict consensus trees; full tree given in Supplementary Data S3). The result supports the monophyly of Microhylidae and of most subfamilies with two important exceptions. Scaphiophryninae is polyphyletic: Scaphiophryne is the sister taxon of a monophyletic Cophylinae, whereas Paradoxophyla is the sister taxon of Kalophryninae. The phylogenetic position of Paradoxophyla is uncertain, with different analyses reporting different conclusions regarding whether it is the sister taxon of Scaphiophryne. On the basis of larval morphology, Haas (2003) did not recover a monophyletic Scaphiophryninae, whereas most analyses based on DNA sequence data support monophyly of the subfamily. Hoplophryne (Hoplophryninae) is nested within Gastrophryninae but with marginal support. We refrain from commenting on these issues at the moment and focus on cophyline systematics.

Cophylinae is weakly supported as the sister taxon of Scaphiophryninae, but it is well supported as a monophyletic group. Anodonthyla, Cophyla, Platypelis, and Plethodontohyla are unambiguously corroborated as monophyletic groups. Cophyla and Platypelis are sister taxa. In PELOSO, C. berara was nested inside Platypelis, whereas here we found this species within a monophyletic Cophyla (in accordance to SCHERZ; see Supplementary Data S3).

The unambiguous monophyly of Stumpffia is rejected, as S. tridactyla is recovered as the sister taxon of SCHERZ's Anilany (A. helenae + an unnamed species tentatively assigned to this genus by SCHERZ) (Fig. 4A). It is noteworthy that this 
relationship received very low support (JK: 40), which attests to the unstable relationship of this taxon to the nuances of different optimality criteria (see also Bayesian versus Parsimony inference in SCHERZ) for choosing among trees. To force the monophyly of Stumpffia (S. tridactyla as the sister taxon of all other Stumpffia) a single branch rearrangement is necessary, and the resulting tree requires 83466 (two transformations longer than the strict consensus) (Fig. 4B).

Rhombophryne is monophyletic although an unnamed species previously recognized as Stumpffia by two separate phylogenetic analyses (ZCMV 12404: Stumpffia spCa34 in Perl et al. 2014 and SCHERZ; Stumpffia sp39 in Klages et al., 2013) is nested inside the genus. These two species (Rhombophryne Rhombophryne spCa07 + Stumpffia spCa34) are collectively called Clade B (Fig. 4). SCHERZ's parsimony analysis did not recover Clade B. On the other hand, SCHERZ's Bayesian analysis recovered Clade B as the sister taxon of all Stumpffia (except for S. tridactyla, which in turn is the sister species of this clade + all remaining Stumpffia). To force SCHERZ's arrangement onto our favored tree, two rearrangements are needed, and the resulting tree is 83879 transformations (415 steps longer than the optimal topology) (Fig. 4D).

Two additional samples previously identified as unnamed Stumpffia by the phylogenetic analysis of Perl et al. (2014) were not found to be members of the Stumpffia clade. Stumpffia spCa15 + Scumpffia spCa16, instead, form the sister clade of Plethodontohyla with modest support (JK: 56: Fig 4). This was already reported in SCHERZ (Bayesian analysis) and we corroborate their findings - a new generic name might be needed whenever these two unnamed species are described. 


\subsection{Optimal taxonomic conclusions}

Clearly, Stumpffia is not assuredly monophyletic with respect to both Rhombophryne and Anilany. Although there are conspicuous topological differences, this result is in accordance to the phylogenetic analysis of PELOSO, and with the parsimony analysis of SCHERZ. Furthermore, the phenotypic divergence between these three taxa is considerably more subtle than that reported in SCHERZ (Supplementary Data S1).

Cophyla and Platypelis are monophyletic, sister taxa; therefore, the taxonomic conundrum involving both genera persists. Considering our topology alone, the decision to maintain both genera as valid or as a single taxonomic unit (for which Platypelis has priority) seems subjective and a matter of opinion. However, given previous evidence that the relationships between these two genera are highly unstable (PELOSO, SCHERZ, but also Pyron and Wiens, 2011; Rakotoarison et al., 2015), and the fact that there are no known morphological synapomorphies that would support either genus as monophyletic (Glaw and Vences, 1994, 2007; Rakotoarison et al., 2015; but see SCHERZ), a single name should suffice to recognize the diversity in the group.

In summary, we find a compelling case remains for the generic recognition of the well-supported monophyletic Platypelis + Cophyla (which thus considers Platypelis as a junior synonym of Cophyla) and Stumpffia + Rhombophryne + Anilany (which thus considers Anilany and Stumpffia as junior synonyms of Rhombophryne). This taxonomy (discussed in Appendix A) also avoids the significant practical problem of trying to diagnose probable paraphyletic genera from each other using dubious morphological characters. 


\section{Acknowledgements}

We thank the editors and one of two anonymous reviewers for critically reviewing the manuscript. This work was supported by the National Science Foundation (NSF-DEB 1311442 to P.L.V.P and D.R.F.) and Conselho Nacional de Desenvolvimento Científico e Tecnológico (grant numbers 400252/2014-7 and 313680/2014-0 to P.L.V.P). 


\section{References}

Andreone, F., Vences, M., Vieites, D.R., Glaw, F., Meyer, A., 2005. Recurrent ecological adaptations revealed through a molecular analysis of the secretive cophyline frogs of Madagascar. Mol. Phylogenet. Evol. 34, 315-322.

Blommers-Schlösser, R.M.A., Blanc, M., 1993. Amphibiens (deuxième partie). Faune de Madagascar 75, 385-530.

Carvalho, A.L., 1954. A preliminary synopsis of the genera of American microhylid frogs. Occas. Pap. Mus. Zool. Univ. Mich. 555, 1-19.

de Sá, R.O., Streicher, J.W., Sekonyela, R., Forlani, M.C., Loader, S.P., Greenbaum, E., Richards, S., Haddad, C.F.B., 2012. Molecular phylogeny of microhylid frogs (Anura: Microhylidae) with emphasis on relationships among New World genera. BMC Evol. Biol. 12, 1-21.

Farris, J.S., Albert, V.A., Källersjo, M., Lipscomb, D., Kluge, A.G., 1996. Parsimony jackknifing outperforms neighbor-joining. Cladistics 12, 99-124.

Felsenstein, J., 1988. Phylogenies from molecular sequences: Inference and reliability. Annu. Rev. Genet. 22.

Glaw, F., Vences, M., 1994. A fieldguide to the amphibians and reptiles of Madagascar. Vences \& Glaw Verlags GbR, Köln, Germany.

Glaw, F., Vences, M., 2007. A field guide to the amphibians and reptiles of Madagascar. Vences \& Glaw Verlags GbR, Köln, Germany.

Goloboff, P.A., 1999. Analysing large datasets in reasonable times: solutions for composite optima. Cladistics 15, 415-428.

Goloboff, P.A., Farris, J.S., Nixon, K.C., 2008. TNT, a free program for phylogenetic analysis. Cladistics 24, 774-786.

Haas, A., 2003. Phylogeny of frogs as inferred from primarily larval characters (Amphibia: Anura). Cladistics 19, 23-89.

Katoh, K., Misawa, K., Kuma, K., Miyata, T., 2002. MAFFT: a novel method for rapid multiple sequence alignment based on Fast Fourier transform. Nucleic Acids Res. 30, 3059-3066.

Kearse, M., Moir, R., Wilson, A., Stones-Havas, S., Cheung, M., Sturrock, S., Buxton, S., Cooper, A., Markowitz, S., Duran, C., Thierer, T., Ashton, B., Mentjies, P., 
Drummond, A., 2012. Geneious Basic: an integrated and extendable desktop software platform for the organization and analysis of sequence data.

Bioinformatics 28, 1647-1649.

Kirchberger, P.C., Sefc, K.M., Sturmbauer, C., Koblmüller, S., 2014. Outgroup effects on root position and tree topology in the AFLP phylogeny of a rapidly radiating lineage of cichlid fish. Mol. Phylogenet. Evol. 70, 57-62.

Klages, J., Glaw, F., Köhler, J., Müller, J., Hipsley, C.A., Vences, M., 2013. Molecular, morphological and osteological differentiation of a new species of microhylid frog of the genus Stumpffia from northwestern Madagascar. Zootaxa 3117, 280 300 .

Köhler, J., Vences, M., D'Cruze, N., Glaw, F., 2010. Giant dwarfs: discovery of a radiation of large-bodied 'stump-toed frogs' from karstic cave environments of northern Madagascar. J. Zool. 282, 21-38.

Maddison, W.P., Maddison, D.R., 2016. Mesquite: a modular system for evolutionary analysis. Version 3.11. Available at: http://mesquiteproject.org

Peloso, P.L.V., Frost, D.R., Richards, S.J., Rodrigues, M.T., Donnellan, S., Matsui, M., Raxworthy, C.J., Biju, S.D., Lemmon, E.M., Lemmon, A., Wheeler, W.C., 2015. The impact of Anchored Phylogenomics and taxon sampling on phylogenetic inference in narrowmouthed frogs (Anura, Microhylidae). Cladistics 32, 113-140.

Perl, R.G.B., Nagy, Z.T., Sonet, G., Glaw, F., Wollenberg, K.C., Vences, M., 2014. DNA barcoding Madagascar's amphibian fauna. Amphibia-Reptilia 35, 197-206.

Pyron, R.A., Wiens, J.J., 2011. A large-scale phylogeny of Amphibia including over 2,800 species, and a revised classification of extant frogs, salamanders, and caecilians. Mol. Phylogenet. Evol. 61, 543-583.

Rakotoarison, A., Crottini, A., Müller, J., Rödel, M.O., Glaw, F., Vences, M., 2015. Revision and phylogeny of narrow-mouthed treefrogs (Cophyla) from northern Madagascar: integration of molecular, osteological, and bioacoustic data reveals three new species. Zootaxa 3937, 61-89.

Sankoff, D. 1975., Minimal mutation trees of sequences. SIAM J. App. Math. 28: 35-42.

Sankoff, D., Cedergren, R.J., 1983. Simultaneous comparison of three or more sequences related by a tree. In: Sankoff, D., Kruskal, J.B. (Eds.), Time warps, string edits, 
and macromolecules: the theory and practise of sequence comparison. AddisonWesley, Reading, MA, pp. 253-264.

Scantlebury, D.P., 2013. Diversification rates have declined in the Malagasy herpetofauna. Proc. R. Soc. B 280, doi: 10.1098/rspb.2013.1109.

Scherz, M.D., Vences, M., Rakotoarison, A., Andreone, F., Köhler, J., Glaw, F., Crottini, A., 2016. Reconciling molecular phylogeny, morphological 1 divergence and classification of Madagascan narrow-mouthed frogs (Amphibia: Microhylidae). Mol. Phylogenet. Evol. 100, 372-381.

Swofford, D.L., 2002. Phylogenetic analysis using parsimony (* and other methods). Version 4. Sinauer Associates, Sunderland, MA.

Vaidya, G., Lohman, D.J., Meier, R., 2011. SequenceMatrix: concatenation software for the fast assembly of multi-gene datasets with character set and codon information. Cladistics 27, 171-180.

van der Meijden, A., Vences, M., Hoegg, S., Boistel, R., Channing, A., Meyer, A., 2007. Nuclear gene phylogeny of narrow-mouthed toads (Family: Microhylidae) and a discussion of competing hypotheses concerning their biogeographical origins. Mol. Phylogenet. Evol. 44, 1017-1030.

Vences, M., Andreone, F., Glaw, F., 2005. A new microhylid frog of the genus Cophyla from a transitional forest in northwestern Madagascar. Afr. Zool. 40, 143-149.

Vences, M., Guayasamin, J.M., Miralles, A., De la Riva, I., 2013. To name or not to name: Criteria to promote economy of change in Linnaean classification schemes. Zootaxa 3636, 201-244.

Wheeler, W.C., 1995. Sequence alignment, parameter sensitivity, and the phylogenetic analysis of moleculardata. Syst. Biol. 44, 321-331.

Wheeler, W.C., 1996. Optimization alignment: the end of multiple sequence alignment in phylogenetics? Cladistics 12, 1-9.

Wilberg, E.W., 2015. What's in an Outgroup? The impact of outgroup choice on the phylogenetic position of Thalattosuchia (Crocodylomorpha) and the origin of Crocodyliformes. Syst. Biol. 64, 621-637. 
Wollenberg, K.C., Vieites, D.R., van der Meijden, A., Glaw, F., Cannatella, D.C., Vences, M., 2008. Patterns of endemism and species richness in Malagasy cophyline frogs support a key role of mountainous areas for speciation. Evolution 62, 1890-1907. Zweifel, R.G., 1972. Results of the Archbold Expeditions No. 97. A revision of the frogs of the subfamily Asterophryninae family Microhylidae. Bull. Am. Mus. Nat. Hist. 148, 413-546. 


\section{Appendix A}

\section{The future of generic taxonomy of Cophylinae: few monophyletic genera, or several}

\section{likely non-monophyletic ones?}

\section{$\underline{\text { A1. Cophyla }}+\underline{\text { Platypelis }}$}

These two genera are almost indistinguishable on the basis of external morphology (Glaw and Vences, 1994, 2007; Rakotoarison et al., 2015; Vences et al., 2005) and there are very few osteological characters that would unambiguously support such a distinction. Scherz et al. (2016) mention only the condition of the vomer as a potentially diagnostic character. SCHERZ further suggests that the presence of clavicles in Platypelis (versus absence in Cophyla) is diagnostic, but clavicles are present at least in C. puellarum (Rakotoarison et al., 2015). Furthermore, both the vomers and clavicles are known to vary widely in microhylids (Carvalho, 1954; Zweifel, 1972), and their conditions are not well surveyed across the diversity of cophylines (conditions unknown in many Platypelis). Therefore, their use as diagnostic characters should be employed with extreme caution, and be viewed with skepticism.

Even if we consider that phenotypic diagnosability is not a necessity for recognition of taxa (genotypic synapomorphies should suffice), monophyly definitely is. Collectively, Cophyla + Platypelis are easily recognizable as a diagnosable monophyletic

group. Separately, the monophyly of both genera cannot be assumed with such certainty, as current evidence is ambiguous. SCHERZ state that their own paper "and a recent revision (Rakotoarison et al., 2015) have shown that species of Cophyla and Platypelis are monophyletic sister groups". Our interpretation of evidence presented by 
Rakotoarison et al. (2015) is, however, different. Rakotoarison et al. (2015) performed two separate analyses on their dataset (with different amounts of evidence included in each of them) and did not recover a monophyletic Platypelis in one of them. They state that "because the first data set did not support the reciprocal monophyly of Platypelis vs. Cophyla, we assembled a more comprehensive data set of four nuclear and four mitochondrial genes for a reduced set of taxa" Rakotoarison et al. (2015: p 64). Here, we question their interpretation of what a "more comprehensive dataset" is. The first analysis included more taxa (and more terminals per taxon) than the second, whereas the second included more genes. Why the second is considered more comprehensive is unclear, as no logical justification is provided to select one proposal over the other. PELOSO also did not recover a monophyletic Platypelis - the sole species of Cophyla included in their analysis is nested within Platypelis. SCHERZ, with increased taxon sampling did find both genera to be monophyletic.

Our own analysis of the combined data from PELOSO and SCHERZ does support the monophyly of Cophyla and Platypelis (Fig. 2). Recognition of both genera as valid or as synonyms is, in this case, a matter of opinion-ours is that all species from this cluster should be considered members of a single genus: Cophyla.

\section{$\underline{\text { A2. Anilany }}+\underline{\text { Rhombophryne }}+\underline{\text { Stumpffia }}$}

SCHERZ claim the taxonomic decision in PELOSO to synonymize

Rhombophryne and Stumpffia was done without proper evidence, and thus resurrect Stumpffia from the synonymy with Rhombophryne. However, in addition to phylogenetic evidence for the non-monophyly of Rhombophryne with respect to Stumpffia provided in 
PELOSO (Fig. 1), there is additional published evidence to suggest that Rhombophryne and Stumpffia are not monophyletic (Perl et al., 2014; Pyron and Wiens, 2011; Scantlebury, 2013; Wollenberg et al., 2008). To be fair, Wollenberg et al. (2008) had previously suggested the recognition of a distinct genus for Stumpffia helenae and the unnamed taxon from Bemahara (Stumpffia sp. "8" in Wollemberg et al., 2008) - the new genus was, however, not officially named until SCHERZ, almost a decade later (named Anilany therein). Furthermore, the parsimony analysis in SCHERZ recovered a paraphyletic Stumpffia with, curiously, their newly erected genus Anilany nested within it. To support their claim, SCHERZ highlight the differences among the type species of Rhombophryne and Stumpffia as justification for the supposedly easy morphological diagnosability of both genera. There is no argument here that the type species of each genus (respectively $R$. testudo and $S$. psologlossa) are in fact very different from each other. Our concern is when you start to add the variation within the group. For some members of Stumpffia and Rhombophryne, it is impossible to place them in one genus or the other based on morphology alone (therefore the large number of misidentified specimens in museum collections and of sequences in GenBank). "Barcode" identification performed by SCHERZ's co-authors have previously identified several unnamed species of Stumpffia, some of which were recovered deeply nested within Rhombophryne by SCHERZ and in our analysis (Fig. 2).

Our reanalysis of the combined PELOSO and SCHERZ data does not unambiguously support the monophyly of Stumpffia. We therefore support the claim in PELOSO that Stumpffia should be considered a junior synonym of Rhombophryne. 
Furthermore, given our phylogenetic results, we also consider that Anilany should be considered a synonym of Rhombophryne.

This taxonomy solves the long-standing problem of Stumpffia paraphyly (Perl et al., 2014: PELOSO, SCHERZ; Pyron and Wiens, 2011; Scantlebury, 2013; Wollenberg et al., 2008) and would obviously be more useful and avoid practical problems of generic assignment based on phenotype (see also Supplementary Data S1). The alternative to this taxonomy would be to name another monotypic genus to accommodate Stumpffia tridactyla - this is the preferred action by SCHERZ. 
Fig. 1. Cophyline section of the phylogenetic tree of PELOSO with the original identifications (left) and updated identification provided by SCHERZ (right: corrected identification labeled in red). Bars after taxon names refer to generic names advocated in PELOSO and SCHERZ. Note that even after sample re-identifications, the taxonomy proposed by SCHERZ would still be non-monophyletic according to this topology. Tree based on 73 loci and direct optimization parsimony.

Fig. 2. Strict consensus (part) of five equally most parsimonious trees of the combined data of PELOSO and SCHERZ. Numbers on branches are Jackknife values (nodes with $\mathrm{JK}<70$ are marked with a red circle). The complete tree is available as Supplementary Data S3.

Fig. 3. Strict consensus (part) of five equally most parsimonious trees of the combined data of PELOSO and SCHERZ. Numbers on branches are Jackknife values (nodes with $\mathrm{JK}<70$ are marked with a red circle). The complete tree is available as Supplementary Data S3.

Fig. 4. Alternative placements of a few selected taxa with their respective tree scores for parsimony and Maximum Likelihood - Clade A = ('Stumpffia' spCa15 + 'Stumpffia' spCa16). Clade B = ('Rhombophryne' spCa07 + 'Stumpffia' spCa34). (A) Preferred arrangement, based on the results from the parsimony optimization-Clade B is nested in Rhombophryne. (B) Alternative arrangement 1: Stumpffia tridactyla constrained as the sister taxon of all other Stumpffia-Clade B is nested in Rhombophryne. (C) Alternative arrangement 2: Clade B is constrained as the sister taxon of all other Stumpffia. (D) Alternative arrangement 3: Both Clade B and S. tridactyla have their positions constrained - this is the preferred topology in SCHERZ. 
Table 1. Clade instability reflecting on the taxonomy of Cophylinae. TNT4 = Parsimony with gaps as missing data; TNT5 = Parsimony with gaps as a fifth state; POY = Direct Optimization parsimony; ML = Maximum Likelihood; UN = unresolved polytomy; NT = not tested, only a single terminal included; Asterisk $\left(^{*}\right)=$ Monophyletic only after unnamed species are disregarded. $\mathrm{P} \& \mathrm{~W}=$ Pyron and Wiens (2011). RDSA = de Sá et al. (2012). PERL = Perl et al. (2014). Monophyly verified using the taxonomy proposed in SCHERZ.

\begin{tabular}{|c|c|c|c|c|c|c|c|c|c|c|}
\hline \multirow[t]{2}{*}{ Clade Arrangement } & \multirow{2}{*}{$\begin{array}{c}\text { P\&W } \\
\text { ML }\end{array}$} & \multirow{2}{*}{$\begin{array}{c}\text { DESA } \\
\text { ML }\end{array}$} & \multirow{2}{*}{$\begin{array}{c}\text { PERL } \\
\text { ML }\end{array}$} & \multirow[b]{2}{*}{ TNT4 } & \multicolumn{2}{|c|}{ PELOSO } & \multirow[b]{2}{*}{ POY } & \multicolumn{2}{|c|}{ SCHERZ } & \multirow{2}{*}{$\begin{array}{c}\text { PRESENT } \\
\text { STUDY } \\
\text { TNT5 }\end{array}$} \\
\hline & & & & & TNT5 & ML & & $\mathbf{T N T}^{1}$ & ML & \\
\hline Cophyla monophyletic & yes & NT & yes & UN & NT & NT & NT & yes & yes & yes \\
\hline Platypelis monophyletic & yes & NT & no & UN & no & yes & no & yes & yes & yes \\
\hline Rhombophryne monophyletic & yes & yes & no & no & UN & yes & no & no & yes* & yes* \\
\hline Stumpffia monophyletic & no* & yes & no & yes & yes & yes & no & no & yes* & no \\
\hline Cophyla + Platypelis monophyletic & no & NT & no & UN & yes & yes & yes & yes & yes & yes \\
\hline $\begin{array}{l}\text { Rhombophryne + Stumpffia } \\
\text { monophyletic }\end{array}$ & no & yes & no & yes & yes & yes & yes & no & no & no \\
\hline
\end{tabular}

${ }^{1}$ It is unclear whether SCHERZ's parsimony analysis optimized gaps as missing data or as a fifth nucleotide state (the latter was assumed because it is TNT's default) or as missing data. 


\section{Original ID}

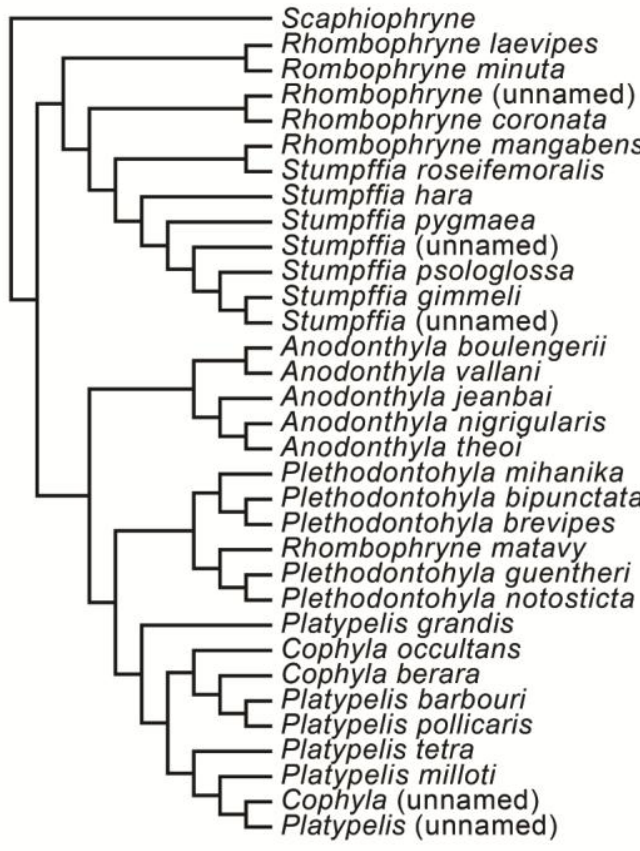

(unnamed)

Anodonthyla

Rhombophryne

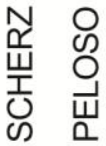

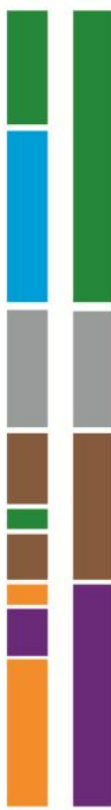

Cophyla

Stumpffia

\section{Corrected ID}

Scaphiophryne

Rhombophryne laevipes

Rombophryne (unnamed)

Rhombophryne (unnamed)

Rhombophryne coronata

Stumpffia (unnamed)

Stumpffia (unnamed)

Stumpffia hara

Stumpffia pygmea

Stumpffia (unnamed)

Stumpffia (unnamed)

Stumpffia gimmeli

Stumpffia (unnamed)

Anodonthyla boulengerii

Anodonthyla vallani

Anodonthyla jeanbai

Anodonthyla nigrigularis

Anodonthyla theor

Plethodontohyla mihanika

Plethodontohyla bipunctata

Plethodontohyla (unnamed)

Plethodontohyla fonetata

Plethodontohyla guentheri

Plethodontohyla guentheri

Platypelis grandis

Platypelis tsaratananaensis Cophyla berara

Platypelis (unnamed)

Platypelis pollicaris

Platypelis tetra

Platypelis milloti

Platypelis (unnamed)

Platypelis (unnamed)

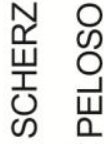

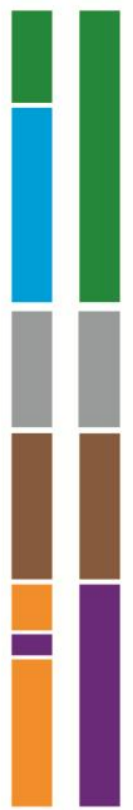

Platypelis

Plethodontohyla 
$A$

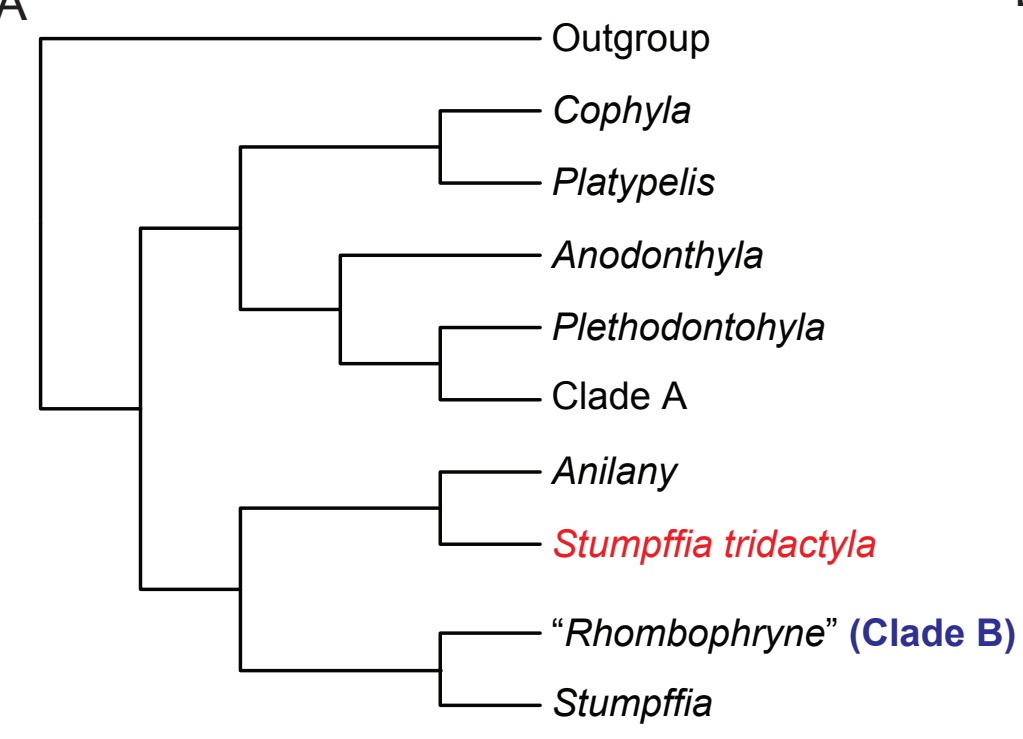

\section{Best Parsimony Tree}

Tree Length: 83464

-logL: 418542.9712

C

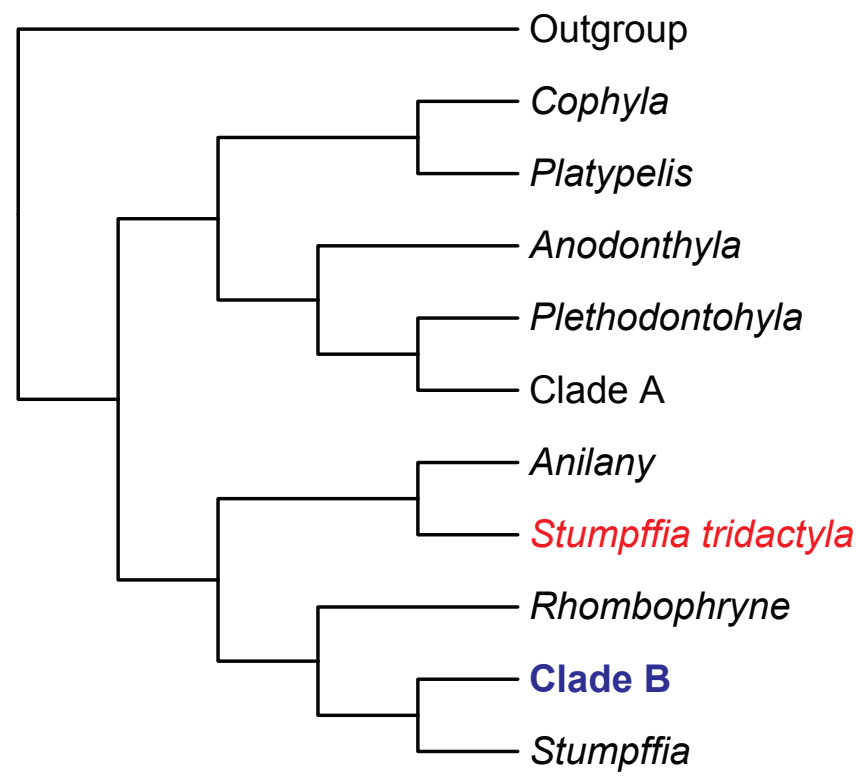

\section{Alternative 2}

Tree Length: 83481 -logL: 418570.5086

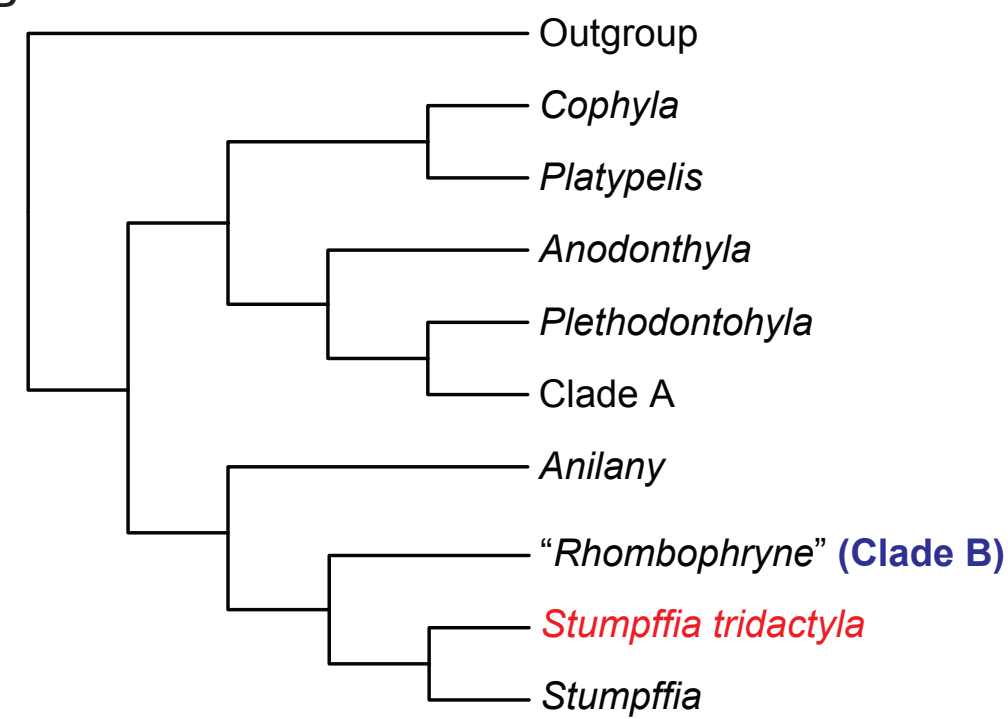

Alternative 1 (= best ML topology)

Tree Length: 83466

-logL: 418515.2068

D

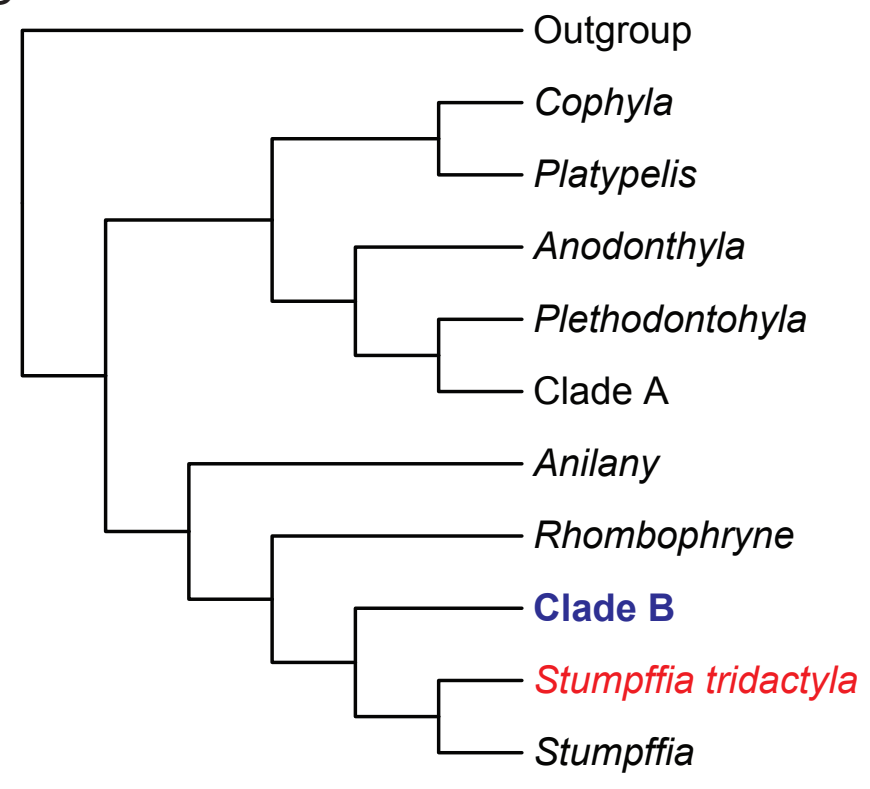

Alternative 3 (= SCHERZ's arrangement)

Tree Length: 83879

-logL: 418535.6437 


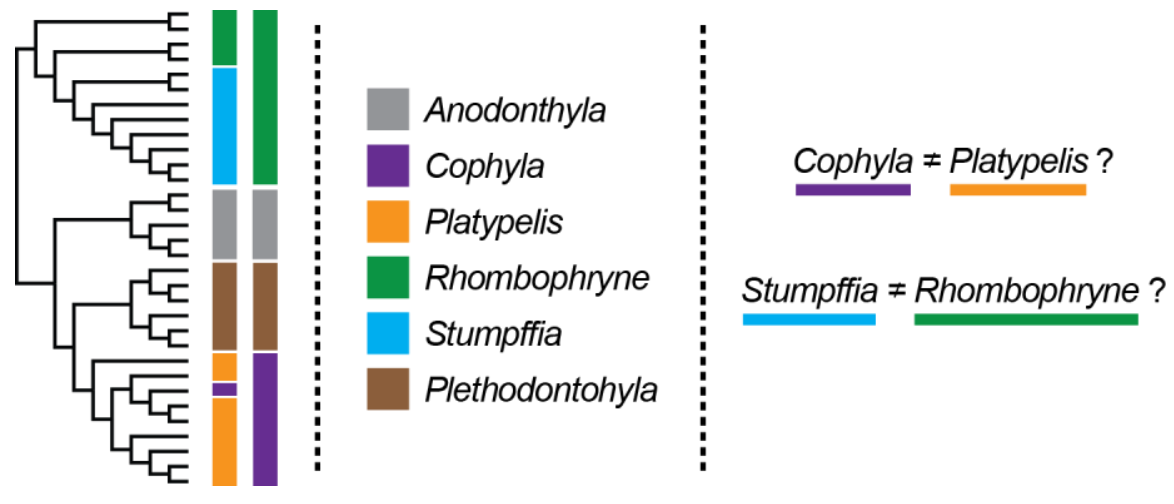

